\title{
Short-term effects of unilateral lesion of the primary motor cortex (M1) on ipsilesional hand dexterity in adult macaque monkeys
}

\author{
Shahid Bashir • Mélanie Kaeser • Alexander Wyss • Adjia Hamadjida • \\ Yu Liu · Jocelyne Bloch • Jean-François Brunet • Abderraouf Belhaj-Saif • \\ Eric M. Rouiller
}

Received: 19 January 2011/ Accepted: 1 May 2011/Published online: 20 May 2011

(C) The Author(s) 2011. This article is published with open access at Springerlink.com

\begin{abstract}
Although the arrangement of the corticospinal projection in primates is consistent with a more prominent role of the ipsilateral motor cortex on proximal muscles, rather than on distal muscles involved in manual dexterity, the role played by the primary motor cortex on the control of manual dexterity for the ipsilateral hand remains a matter a debate, either in the normal function or after a lesion. We, therefore, tested the impact of permanent unilateral motor cortex lesion on the manual dexterity of the ipsilateral hand in 11 macaque monkeys, within a time window of 60 days post-lesion. For comparison, unilateral reversible pharmacological inactivation of the motor cortex was produced in an additional monkey. Manual dexterity was assessed quantitatively based on three motor parameters derived from two reach and grasp manual tasks. In contrast to the expected dramatic, complete deficit of manual dexterity of the contralesional hand that persists for several weeks, the impact on the manual dexterity of the ipsilesional hand was generally moderate (but statistically significant) and, when present, lasted less than 20 days. Out of the 11 monkeys, only 3 showed a deficit of the ipsilesional hand for 2 of the 3 motor parameters, and 4 animals had a deficit for only one motor parameter. Four
\end{abstract}

S. Bashir, M. Kaeser, A. Wyss, and A. Hamadjida are equal first authors.

S. Bashir - M. Kaeser - A. Wyss - A. Hamadjida · Y. Liu ·

A. Belhaj-Saif · E. M. Rouiller $(\varangle)$

Department of Medicine and Program in Neurosciences, Faculty of Sciences, University of Fribourg, Chemin du Musée

5, 1700 Fribourg, Switzerland

e-mail: Eric.Rouiller@unifr.ch

J. Bloch · J.-F. Brunet

Department of Neurosurgery, Lausanne University Hospital

(CHUV), Rue du Bugnon 46, 1011 Lausanne, Switzerland monkeys did not show any deficit. The reversible inactivation experiment yielded results consistent with the permanent lesion data. In conclusion, the primary motor cortex exerts a modest role on ipsilateral manual dexterity, most likely in the form of indirect hand postural control.

Keywords Permanent lesion - Reversible lesion · Primate

\section{Introduction}

In primates, the corticospinal projection system plays a major role in the control of skilled movements performed with the contralateral hand (see Lemon 2008, for review), consistent with the notion that most corticospinal axons addressing motoneurons that control distal forelimb muscles decussate (about $85-98 \%$ of all corticospinal axons; Rouiller et al. 1996; Lacroix et al. 2004; Rosenzweig et al. 2009; Yoshino-Saito et al. 2010). In contrast, the small contingent of uncrossed corticospinal axons (about 2-15\%) terminates mainly in zones of the cervical cord comprised of the motoneurons of proximal and axial muscles. As a consequence, it is generally assumed that the motor cortex limits its control on the ipsilateral forelimb to movements executed by proximal muscles (see Ganguly et al. 2009; Bradnam et al. 2010, for recent functional data). Nevertheless, a possible contribution of the motor cortex to the control of ipsilateral skilled hand movements remains a matter of debate, as an activation of the motor cortex associated with skilled movements performed with the ipsilateral hand was found in normal human subjects (e.g. Kim et al. 1993; Sadato et al. 1996; Catalan et al. 1998; Kawashima et al. 1998; Cramer et al. 1999; Ehrsson et al. 2000; Porro et al. 2000; Hummel et al. 2003; Rau et al. 2003; Verstynen et al. 2005). The activity in the ipsilateral 
motor cortex was related to the complexity of the task (e.g. Catalan et al. 1998; Hummel et al. 2003; Verstynen et al. 2005), and compared to the site of activation in the contralateral hemisphere, it was shifted ventrally, laterally and anteriorly (Cramer et al. 1999; Verstynen et al. 2005).

In response to unilateral transcranial magnetic stimulation (TMS) of the motor cortex, motor-evoked potentials (MEPs) can be recorded from ipsilateral distal muscles (Wassermann et al. 1991; Alagona et al. 2001; Chen et al. 2003; Ziemann et al. 1999), although pre-contraction of the target muscles was required. In other studies, however, no such ipsilateral MEP activity was observed in hand muscles (Carr et al. 1994; Netz et al. 1997; Bawa et al. 2004). Ipsilateral MEPs are related to the degree of handedness (Bernard et al. 2011). When TMS was used to generate a transient inactivation of the motor cortex while the subject was performing hand motor tasks with the ipsilateral hand, deficits were observed in a sequential finger task (Chen et al. 1997), and in grip-lift and in step-tracking tasks (Davare et al. 2007). This effect may be mediated by indirect corticoreticulospinal fibers (Chen et al. 1997) or through the opposite motor cortex via transcallosal fibers, although the hand representations of the two motor cortices are less strongly connected via the corpus callosum than other body territories (Jenny 1979; Rouiller et al. 1994). Finally, a study by Foltys et al. (2001) demonstrated that a perturbation of the ipsilateral motor cortex with TMS affects the reaction time to generate simple unimanual or bimanual movements.

The possible role of the ipsilateral motor cortex in the control of hand movements is indirectly supported by motor deficits of the ipsilesional hand observed after unilateral stroke (Hermsdörfer and Goldenberg 2002; Hermsdörfer et al. 2003; Sunderland et al. 1999; Sunderland 2000; Yarosh et al. 2004; Wetter et al. 2005; Nowak et al. 2007; Chestnut and Haaland 2008; Noskin et al. 2008). A clear limitation of lesional data in human subjects is the highly variable extent of the lesion as well as its location, rarely if ever restricted to the primary motor cortex. Furthermore, depending on the time separating the lesion from the observation, often several weeks, months or years post-lesion, a re-organization of the motor system may have significantly modified or adapted the performance of the ipsilesional hand, as compared to the prelesion performance (e.g. Kaeser et al. 2010). Finally, the lesion studies in patients are based on comparison with a group of normal subjects, a procedure inherently confounded by large inter-individual variability.

Given the above-outlined limitations, the necessity of using a non-human primate model becomes evident, especially considering the fact that manual dexterity is considered to be a prerogative of primates (see Lemon 2008, for review), and monkeys such as macaques exhibit considerable manual dexterity. In macaques, using the technique of intracortical microstimulation (ICMS), in a restricted sub-region of the primary motor cortex (M1), located at the limit between the standard hand and face representations of the contralateral body side, ICMS elicited EMG responses in distal muscles not only on the contralateral forelimb as expected, but also in distal muscles on the ipsilateral side (Aizawa et al. 1990). Moreover, in various tasks executed with one or the other hand, several studies demonstrated the presence of neuronal activity in M1 correlated with movements of the ipsilateral hand (Matsunami and Hamada 1981; Aizawa et al. 1990; Chen et al. 1991; Donchin et al. 1998, 2002; Kermadi et al. 1998, 2000; Kazennikov et al. 1999; Cisek et al. 2003). However, it cannot be completely ruled out that such ipsilaterally related neuronal activity may be, at least in part, due to parallel activation of proximal muscles, or that it may correspond to an inhibition of movements with the opposite hand in unimanual tasks (for instance to prevent mirror movements). Due to these limitations of interpretation, the goal of the present study was to use the non-human primate model to assess the role of M1 in the control of the ipsilateral hand using an experimental lesional approach. The advantages of this model are multifold: (1) each trained animal can be used as its own control (by comparing prelesion vs. post-lesion performance); (2) observations can be conducted at very early time points post-lesion; and (3) the lesion can be mainly restricted to M1. In a previous study that employed small lesions of the hand area of M1, some paralyses of the ipsilateral hand were cursorily mentioned (Glees and Cole 1950; Cole and Glees 1952). The present study aims at extending these initial data using: (1) a larger population of monkeys; (2) a more quantitative assessment of manual performance; and (3) lesions whose extent and location are guided electrophysiologically by ICMS. Furthermore, the effect of M1 lesion was tested on the ipsilateral hand following both permanent and reversible lesions.

\section{Methods}

The present data have been derived from a comprehensive long-term experiment, conducted on 11 adult macaque monkeys (Macaca fascicularis) subjected to a unilateral permanent lesion of M1 (see Table 1; Fig. 1a) and 1 additional monkey subjected to pharmacological reversible inactivation of M1 unilaterally. All experiments were conducted in accordance with the Guide for the Care and Use of Laboratory Animals (ISBN 0-309-05377-3; 1996) and approved by local (Swiss) veterinary authorities.

In our animal facility, monkeys were housed in rooms of $12 \mathrm{~m}^{3}$, in which usually $2-4$ monkeys were free to move 
Table 1 List of monkeys subjected to permanent primary motor cortex lesion and included in the present study with identification code

\begin{tabular}{|c|c|c|c|c|c|c|c|c|c|c|c|}
\hline & $\begin{array}{l}\text { Mk- } \\
\mathrm{CE}\end{array}$ & $\begin{array}{l}\text { Mk- } \\
\text { JU }\end{array}$ & $\begin{array}{l}\text { Mk- } \\
\text { GE }\end{array}$ & $\begin{array}{l}\text { Mk- } \\
\text { RO }\end{array}$ & $\begin{array}{l}\text { Mk- } \\
\text { BI }\end{array}$ & Mk-VA & Mk-SL & Mk-MO & Mk-AV & Mk-JO & Mk-JA \\
\hline Treatment & None & None & None & None & None & $\begin{array}{l}\text { Anti- } \\
\text { Nogo-A } \\
\text { antibody }\end{array}$ & $\begin{array}{l}\text { Anti- } \\
\text { Nogo-A } \\
\text { antibody }\end{array}$ & $\begin{array}{l}\text { Anti- } \\
\text { Nogo-A } \\
\text { antibody }\end{array}$ & $\begin{array}{l}\text { Sham- } \\
\text { cell } \\
\text { therapy }\end{array}$ & $\begin{array}{l}\text { Cell } \\
\text { therapy }\end{array}$ & $\begin{array}{l}\text { Cell } \\
\text { therapy }\end{array}$ \\
\hline $\begin{array}{l}\text { Age at time of lesion (rounded } \\
0.5 \text { year) }\end{array}$ & 4.5 & 5 & 5 & 4 & 5 & 5.5 & 5.5 & 5.5 & 3.5 & 3.5 & 4 \\
\hline Weight at time of lesion & 3.8 & 3.6 & 2.8 & 3.2 & 5 & 4.9 & 4.6 & 5.6 & 4.3 & 3.4 & 4.3 \\
\hline Volume of ibotenic acid injected $(\mu \mathrm{l})$ & 40 & 40 & 13 & 18 & 29.7 & 15.5 & 18 & 20 & 15 & 15 & $38^{\mathrm{a}}$ \\
\hline $\begin{array}{l}\text { No. of ICMS sites injected with } \\
\text { ibotenic acid }\end{array}$ & 21 & 21 & 13 & 12 & 29 & 11 & 12 & 20 & 10 & 10 & 38 \\
\hline $\begin{array}{l}\text { Total volume of lesion }\left(\mathrm{mm}^{3}\right) \text {, gray } \\
\text { matter (motor cortex }+ \text { post-central } \\
\text { gyrus) }\end{array}$ & 112.8 & 63.01 & 48.7 & 14 & 20.13 & 20 & 78.2 & 41.8 & 33.2 & 33.6 & 22.2 \\
\hline $\begin{array}{l}\text { Volume of lesion in post-central gyrus } \\
\left(\mathrm{mm}^{3}\right)\end{array}$ & 10.1 & 0 & 7.6 & 0 & 0 & 5.8 & 1.8 & 0 & 0 & 3.8 & 2.5 \\
\hline $\begin{array}{l}\text { Lesion spread subcortically to the } \\
\text { white matter }\left(\mathrm{mm}^{3}\right)\end{array}$ & 86.5 & 28.9 & 0 & 0 & 0 & 0 & 130.6 & 0 & 69.8 & 23.6 & 38.4 \\
\hline
\end{tabular}

Mk-LA (involved only in the transient inactivation of M1 with infusion of muscimol) was 5 years old and weighted $2.6 \mathrm{~kg}$. A total volume of $15 \mu \mathrm{l}$ of muscimol was infused in M1, at 10 sites, previously identified based on ICMS (see text)

${ }^{a}$ In Mk-JA, nearly the same amount of ibotenic acid was injected as in the first two monkeys (Mk-CE and Mk-JU). However, in contrast to the other two monkeys, Mk-JA suffered several epileptic attacks immediately after the lesion. The monkey Mk-JA was treated with an anti-epileptic drug (Luminal), preventing other episodes. The anti-epileptic drug is known to counteract the excitotoxic effect of ibotenic acid, yielding a smaller volume of lesion as compared to the other two monkeys which received a comparable volume of ibotenic acid

and to interact with each other. ${ }^{1}$ Before daily behavioral testing in the morning, the animal caretaker moved the monkeys to temporary cages for subsequent transfer to a primate chair, in which the monkeys were transported to the behavioral laboratory. The monkeys had free access to water and were not food deprived. The rewards (pellets) obtained during the behavioral tests were the first daily access to food. After completion of the behavioral tests, the monkeys received additional food (fruits, cereals). The body weight of the animals was monitored on each working day. In case the body weight dropped by $10 \%$ or more, the experiment was interrupted until the monkey regained the lost weight (this criterion for interruption was not met during the course of the present experiments).

\section{Treatments}

The 11 monkeys subjected to unilateral permanent lesion of the motor cortex were included in two pilot studies aimed at assessing the possible effects of two different treatments: (a) anti-Nogo-A antibody treatment; (b) cell therapy with injection of autologous adult progenitor cells collected from the prefrontal cortex (see Brunet et al. 2005; Kaeser et al. 2011). The anti-Nogo-A antibody treatment

\footnotetext{
1 A new Swiss regulation introduced in September 2010 now requires that a volume of at least $45 \mathrm{~m}^{3}$ be given to a group of up to five macaque monkeys.
}

has been found to significantly enhance functional recovery and sprouting of corticospinal axons after cervical cord injury in rats (Gonzenbach and Schwab 2008, for review) and primates (Freund et al. 2006, 2007, 2009). The same strategy was tested here for a sub-group of three monkeys (Mk-VA, Mk-SL, Mk-MO) and compared with a subgroup of five monkeys also subjected to a unilateral lesion of the motor cortex but without any treatment (Mk-CE, Mk-JU, Mk-GE, Mk-RO and Mk-BI; see Table 1). As outlined in Table 1, three monkeys were included in the pilot cell therapy project, two monkeys (Mk-JO and Mk-JA) received an implantation of adult progenitor cells in the vicinity of the cortical lesion, whereas one monkey (Mk-AV) was a sham control (infusion of vehicle only). The therapeutic effect of the two treatments on the contralesional hand is reported elsewhere (e.g. Kaeser et al. 2011). The possible impact of the treatments on the ipsilesional hand will be addressed in "Discussion".

\section{Behavioral analysis}

Monkeys were trained to perform two variations of a manual skill task consisting of grasping small food pellets using a precision grip, namely the opposition of the thumb and index finger. Food pellets were made of dried banana or glucose powder that is compressed in a round shape of about $4 \mathrm{~mm}$ in diameter. Dried raisins were occasionally given to increase the motivation of the animals, e.g. to 
Fig. 1 a Location and extent of the permanent unilateral lesion of the M1 hand representation as seen on corresponding lateral views of the brain for 11 monkeys included in the present study (see Table 1). The lesion territory is represented in $r e d$, as derived from the lesioned zone of cerebral cortex (gray matter) visible on consecutive frontal histological sections. Spread of the lesion to the subcortical white matter below the gray matter is not represented here, except in monkey Mk-SL in which a subcortical white matter territory was lesioned (gray spot), in a region located more medially than the red territory. The motor cortex lesion was performed in all monkeys on the left hemisphere, except in Mk$\mathrm{JU}$ in which the lesion was in the right hemisphere. Six monkeys (top panel) were control animals for two pilot treatment studies: three monkeys were treated with antiNogo-A antibody (middle panel) whereas two monkeys were subjected to an autologous cell therapy (see "Methods" and Table 1). b View of the Modified Brinkman Board (left) and the Brinkman box (right)
A
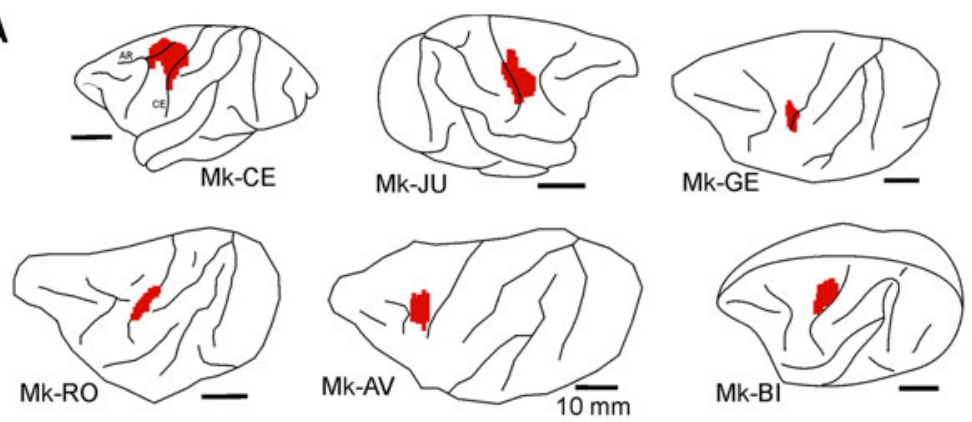

Control monkeys $(n=6)$
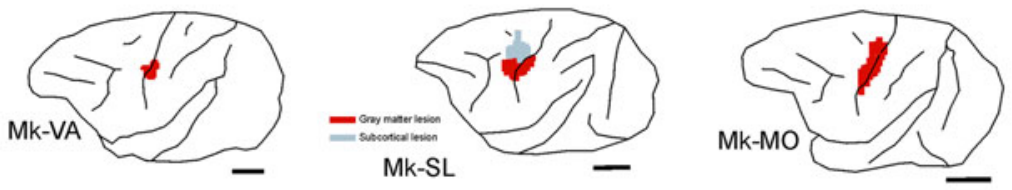

Anti-Nogo-A antibody treated monkeys $(n=3)$
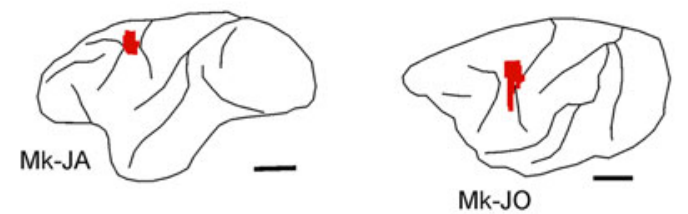

Adult autologous progenitor cell therapy monkeys $(n=2)$

B

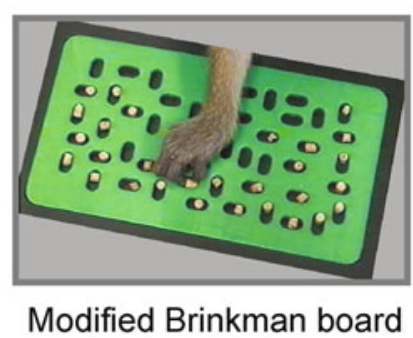

Brinkman box perform a particularly crucial step during training. A daily behavioral session typically lasted $60 \mathrm{~min}$. An initial training period was necessary until the monkeys reached a stable pre-lesion performance, which was then quantitatively determined during a time window ranging from 30 to 128 days before the lesion (Table 1), depending on the specific experimental protocol for each monkey. Postlesion, the behavioral tasks were pursued during several months (see Kaeser et al. 2010, for long-term effects). In the present report, as the goal was to investigate the shortterm effects, the post-lesional behavioral data for the ipsilesional hand were limited to a time window ranging from the day of the lesion up to 60 days post-lesion.

The first manual skill test corresponds to our "Modified Brinkman Board" task (Fig. 1b, left panel), previously described in detail (e.g. Rouiller et al. 1998; Liu and Rouiller 1999; Schmidlin et al. 2004; Freund et al. 2006,
2009; Kaeser et al. 2010, 2011): briefly, the tests were performed on a perspex board $(10 \mathrm{~cm} \times 20 \mathrm{~cm})$ containing 50 randomly distributed slots, each filled with a food pellet at the beginning of the test. Twenty-five slots were oriented horizontally and 25 slots vertically. The dimension of the slots was $15 \mathrm{~mm}$ long, $8 \mathrm{~mm}$ wide and $6 \mathrm{~mm}$ deep. This manual prehension task was executed daily, alternately with one or the other hand, 2-5 times per week for several months before and after the cortical lesion. The performance of each hand was videotaped. In the present study, two parameters were assessed: (1) The retrieval score corresponds to the number of pellets successfully retrieved from the slots and brought to the mouth during $30 \mathrm{~s}$, established separately for the vertical and the horizontal slots; (2) The contact time, defined as the time of contact (in seconds) between the fingers and the pellet, calculated for the first five vertical slots and the first five 
horizontal slots targeted by the monkey in a given daily session (Kaeser et al. 2010).

In parallel, monkeys were trained to perform the "Brinkman box" task (Fig. 1b, right panel), in which a box containing a perspex board of 20 wells was used (10 vertical slots and 10 horizontal slots). The monkey had visual control on its grasping movements within the box and therefore the test is generally comparable to the above Modified Brinkman Board task, except that the number and spatial distribution of slots is different and the hand is constrained to a restricted space, offering fewer degrees of freedom to reach each slot. The "Brinkman box" task was quantified by counting the total time in seconds needed by the monkey to empty the 20 wells. The two manual skill tasks (Modified Brinkman Board and Brinkman box) can be seen on the following web page: http://www.unifr.ch/neuro/ rouiller/motorcontcadre.htm.

\section{Surgical procedures}

After the monkey reached a stable pre-lesion performance level, the monkeys were implanted unilaterally with a chronic, stainless steel or tecapeek chamber giving access to M1, but leaving the dura mater in place (see Schmidlin et al. 2004, for detail). The monkeys were first sedated with i.m. injection of ketamine (Ketalar, $5 \mathrm{mg} / \mathrm{kg}$ ) and premedicated with the analgesic carprofen (Rymadil, $4 \mathrm{mg} / \mathrm{kg}$, s.c.) to reduce pain after surgery, as previously described (Schmidlin et al. 2005; Wannier et al. 2005; Freund et al. 2006, 2007, 2009). The surgical intervention itself was conducted under aseptic conditions, and profound anesthesia was maintained for several hours by i.v. infusion of propofol (mixture of $1 \%$ propofol and $4 \%$ glucose in saline, 1 volume of propofol and 2 volumes of glucose delivered at the rate of $0.1 \mathrm{ml} / \mathrm{min} / \mathrm{kg}$ ). Ketamine was added to the perfusion solution, as previously reported (Freund et al. 2007). After surgery, the animals were treated with antibiotics (ampicillin 10\%, $30 \mathrm{mg} / \mathrm{kg}$, s.c.) and analgesics (pills of Rymadil mixed with food) for several days. Implanted chambers were fixed to the skull with titanium screws and orthopedic cement (Palacos). The inside of the chronic chamber was cleaned daily with Betadine and an antibiotic ointment was spread on the dura mater surface to reduce the risk of infection.

\section{Mapping M1 with intracortical microstimulation (ICMS)}

The surgical goal was to restrict the unilateral lesion mainly to the hand representation in M1. To do so, ICMS sessions were performed to map M1: a tungsten microelectrode (0.1-1 M $\Omega$ impedance, FHC Inc, USA) was used to micro-stimulate $\mathrm{M} 1$, along penetrations at $1 \mathrm{~mm}$ from each other, as previously described in detail (Schmidlin et al. 2004, 2005; Kaeser et al. 2010). Along each electrode track, ICMS was applied below the surface of the dura at intervals of $1 \mathrm{~mm}$, along a trajectory of up to $10 \mathrm{~mm}$ (in the rostral bank of the central sulcus). The effects of ICMS were assessed by visual inspection of the body part (articulation) at which a movement was elicited and at which minimal current (ICMS threshold) it produced the effect. The ICMS map was finally represented in the form of an unfolded map of M1, as previously reported (Park et al. 2001, 2004; Kaeser et al. 2010) and provided the basis with which to guide injections of ibotenic acid in order to produce a lesion of M1 centered on the hand area.

Lesion of M1 hand representation with ibotenic acid (permanent lesion)

The cortical lesion was targeted to the hand representation in M1 on one hemisphere. Ibotenic acid $(10 \mu \mathrm{g} / \mu \mathrm{l}$ in phosphate buffer) was infused using a Hamilton microsyringe at selected ICMS sites of the hand area in M1 unilaterally, as previously reported in detail (Liu and Rouiller 1999). The number of ICMS sites injected and the total volume of ibotenic acid infused in M1 are indicated for each monkey in Table 1. Several minutes after the ibotenic acid infusion, the contralateral hand exhibited a dramatic paralysis (see Liu and Rouiller 1999; Kaeser et al. 2010, 2011).

\section{Reversible inactivation of M1 (transient lesion)}

In one additional monkey (Mk-LA), a pharmacological reversible inactivation of $\mathrm{M} 1$ was induced by infusion of muscimol, as previously reported (Kermadi et al. 1997; Schmidlin et al. 2004). Mk-LA was initially included in the present study of permanent lesion, but it turned out that the injection of ibotenic acid in the left M1 failed and, as assessed histologically, did not produce an identifiable permanent lesion in M1 as in the other monkeys. In SMI-32 material from Mk-LA, there was only a very small territory (about $3 \mathrm{~mm}^{3}$ ) in which SMI-32 positive neurons in layer $\mathrm{V}$ appeared somewhat less densely packed (contrasting with the SMI-32 positive neurons which completely disappeared in the lesion territory in the other 11 monkeys; see Kaeser et al. 2010). In accordance with such a small anatomical disruption, the contralesional hand showed only a small deficit in manual dexterity for a couple of days, and the animal's behavioral performance returned to pre-lesion levels after just 5 days. Thus, for several months following the ineffective ibotenic acid injection, the manual dexterity of both hands was stable and corresponded to the pre-lesion performance. Mk-LA had been implanted with chronic stainless steel chambers on both hemispheres. The intact 
right M1 hand area was thus used for two reversible inactivation sessions, in which the GABA agonist muscimol was infused at ICMS sites within the M1 hand representation area. The Modified Brinkman Board task was performed by Mk-LA before and after the muscimol infusion, offering the possibility to assess the immediate (15 min after infusion) effect on the ipsilesional (right) hand.

\section{Data analysis}

Within the time window of pre- and post-lesion behavioral analysis for each monkey, the daily retrieval score and contact time were plotted as a function of time (days). The pre-lesion period was used to establish the manual performance of reference, the average retrieval score and its standard deviation (SD). On the plots, the average prelesion retrieval score was represented by a thick horizontal line, together with a dashed line positioned at mean retrieval score minus 2SDs. A decrease in the post-lesion retrieval score below the 2SDs was considered as a statistically significant deficit (see Fig. 2). For contact time, a deficit would be signaled by an increase. On the plots, a deficit was considered as statistically significant when contact time was longer than the average pre-lesion contact time plus 2SDs (see Fig. 3). Similarly, for the Brinkman box, a deficit was present when the total time post-lesion exceeded the prelesion average total time +2 SDs (see Fig. 4).

At the end of the experiments, the animals were killed with an overdose of pentobarbital sodium $(90 \mathrm{mg} / \mathrm{kg}$ body weight, i.p.). Transcardiac perfusion with $0.9 \%$ saline $(500 \mathrm{ml})$ was followed by fixative $(4000 \mathrm{ml}$ of $4 \%$ phosphate-buffered paraformaldehyde). The brains were placed in a 30\% solution of sucrose (in phosphate buffer) for cryoprotection during 3-5 days. Sections (50 $\mu \mathrm{m}$ thick) of the brain were cut in the frontal plane and collected in five series. One series of sections was Nissl stained with cresyl violet, whereas a second series of sections was processed to visualize the marker SMI-32, as previously described (Wannier et al. 2005; Beaud et al. 2008). The epitope recognized by the SMI-32 antibody lies on non-phosphorylated regions of neurofilament protein and is only expressed by specific categories of neurons (Campbell and Morrison 1989; Tsang et al. 2006). The two series of sections were then used to reconstruct on consecutive sections the position and extent of the permanent lesion in M1. Finally, the lesion was positioned on a lateral view of the lesioned hemisphere (Fig. 1a). Using an ad hoc function of the Neurolucida software (based on the Cavalieri method), the volume of the cortical lesion (in $\mathrm{mm}^{3}$ ) was extrapolated from the reconstructions of the lesion on consecutive histological sections of the brain (see Table 1; Kaeser et al. 2010).

\section{Results}

Unilateral lesion of the motor cortex

Unilateral lesion of the motor cortex was produced by infusion of ibotenic acid at multiple sites defined by ICMS (see Kaeser et al. 2010). The goal was to permanently inactivate the hand area in M1. The extent and location of the lesion is shown in Fig. 1a on a lateral view of the lesioned hemisphere for the 11 monkeys included in the present study. The lesion extent was variable from one monkey to the next, but on surface views of the brain generally corresponded to a zone of $4-5 \mathrm{~mm}$, thus matching the size of the hand area. In some monkeys, in one dimension or the other, the lesion extended further, for the largest lesions reaching an extent of up to $10 \mathrm{~mm}$. In one monkey (Mk-SL), there was a large zone of subcortical lesion (in the white matter) spreading more medially than the gray matter lesion (Fig. 1a). In some of the other monkeys, subcortical damage was also observed (see Table 1), but it was located below the gray matter injury (and therefore it did not appear on the brain surface views in Fig. 1a).

Effect of permanent unilateral motor cortex (M1) lesion on manual dexterity

\section{Modified Brinkman Board test: retrieval score}

The possible effects of unilateral motor cortex (M1) lesion on the ipsilesional hand was assessed during a short-term time window ranging from 0 to 60 days post-lesion, by comparing the pre-lesion and post-lesion manual performance of each animal in the Modified Brinkman Board task. A first parameter analyzed here is the retrieval score, defined as the total number of pellets retrieved in $30 \mathrm{~s}$ (considering both the vertical and horizontal slots). As illustrated in Fig. 2 for four representative monkeys, the pre-lesion manual performance was generally stable as indicated by the distribution of data points around the average "score" (thick horizontal line). The variability prelesion across daily sessions is represented by the two dashed horizontal lines placed at average retrieval score +2 standard deviations (SDs) and at average retrieval score $-2 \mathrm{SDs}$, respectively.

A first subgroup of 4 monkeys (Mk-JA, Mk-VA, MkBI and Mk-MO) out of 11 showed a small and transient deficit of manual performance of the ipsilesional hand immediately after the lesion of M1 (Table 2). In two monkeys (Mk-JA and Mk-VA), shortly after the lesion (day 0; vertical dashed line), there were a few sessions in which the retrieval score dropped below the dashed line corresponding to the average pre-lesion retrieval score 
Fig. 2 Behavioral data (manual dexterity) obtained from four representative monkeys (Mk-

JA, Mk-VA, Mk-MO and MkGE) for the Modified Brinkman Board task. The manual dexterity of the ipsilesional hand is given by the retrieval score, corresponding to the total number of pellets retrieved in $30 \mathrm{~s}$, as a function of time (days). The day of the M1 lesion is at time zero (vertical dashed line). The retrieval scores for the vertical and horizontal slots were cumulated. The thick horizontal line is the average retrieval score, computed from the pre-lesion daily sessions only. The horizontal dashed lines are for the average retrieval score plus 2SDs and minus 2SDs. For comparison, the retrieval scores (triangles) are given on the right for the contralesional hand for the same monkeys. The period at plateau pre-lesion were of variable duration, depending on the date set for the lesion across monkeys. Similarly, on the right, the post-lesion period shown on the graphs was set depending on the variable time course of recovery across monkeys

\section{Modified Brinkman board (retrieval score)}

\section{Ipsilesional hand}
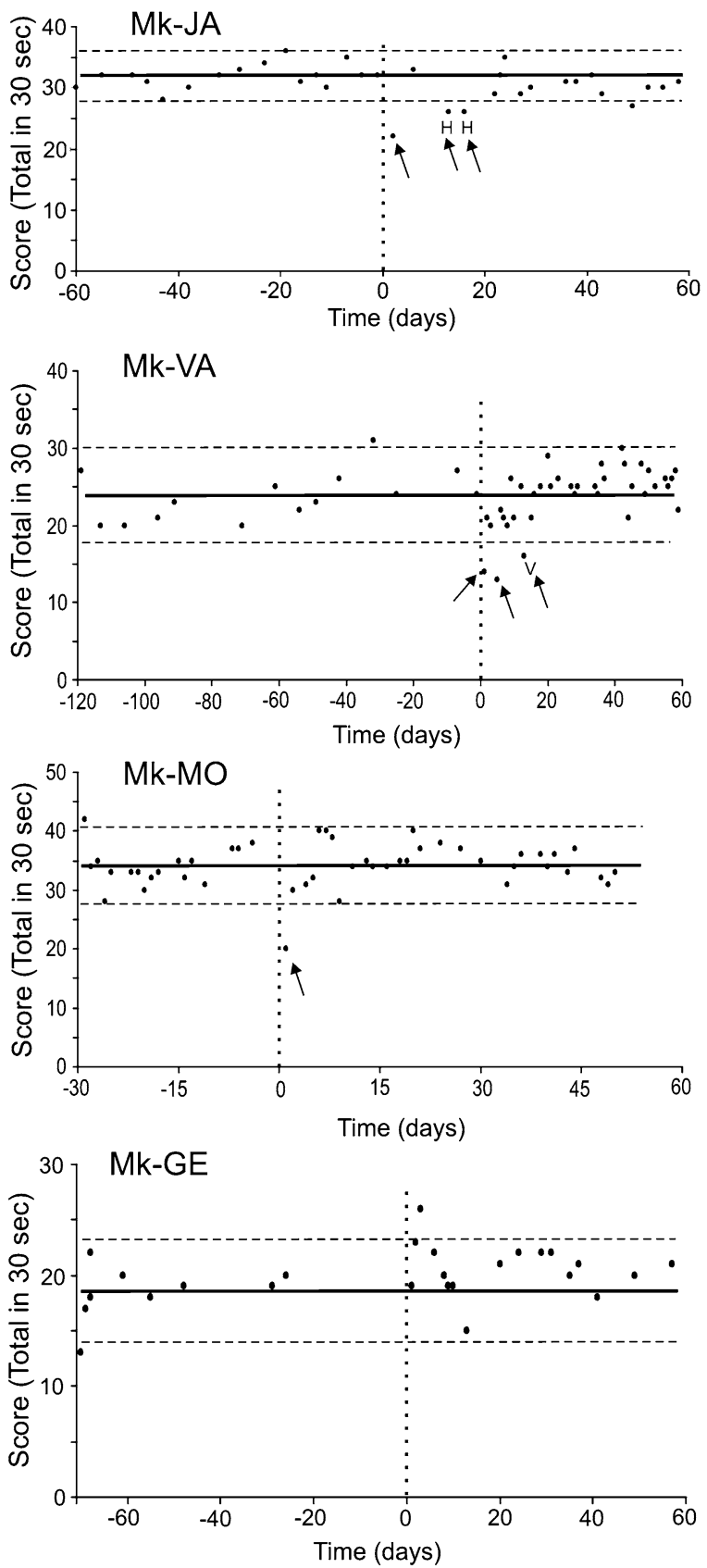
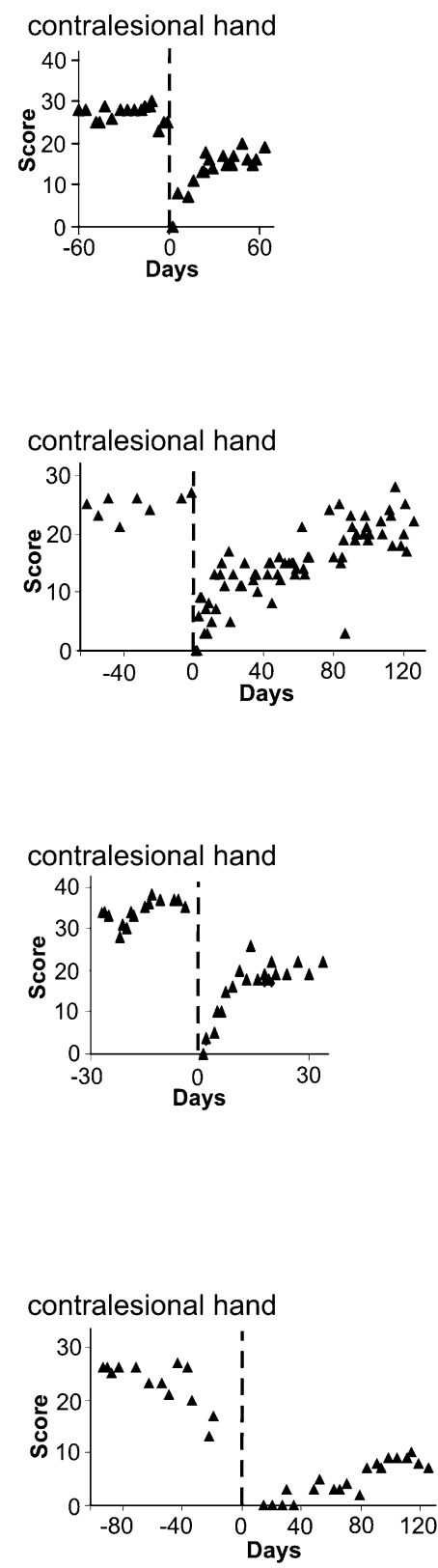

minus 2SDs, considered as the confidence limit for a statistically significant loss of performance for the ipsilesional hand (Fig. 2). Although significant, the deficit remained modest and transitory, as compared to the more devastating and prolonged effect observed in the same monkeys for the contralesional hand (small graphs on the right with retrieval score indicated by triangles in Fig. 2). In these two monkeys, the letters " $\mathrm{H}$ " and "V" represent sessions in which the deficit was significant only due to the horizontal slots $(\mathrm{H})$ or the vertical slots $(\mathrm{V})$, respectively. In the other sessions where retrieval score was lower than the average minus 2SDs, the deficit was significant for both slot orientations. A deficit comparable to those of Mk-JA and Mk-VA was observed for the ipsilesional hand of Mk-BI (not shown). In the fourth monkey of this subgroup (Mk-MO; Fig. 2), the deficit was even more transient, as it was limited to a single daily session shortly after the lesion. 
Fig. 3 Behavioral data (manual dexterity) obtained from three representative monkeys (MkJO, Mk-MO and Mk-RO) for the Modified Brinkman Board task. The manual dexterity of the ipsilesional hand is given by the contact time, corresponding to the time of contact (in seconds) between the fingers and the first five pellets in vertical slots (left column) and the first five pellet in horizontal slots (right column) targeted by the monkey. Along the abscissa, the day of the M1 lesion is at time zero (vertical dashed line). The thick horizontal line is the average contact time, computed from the pre-lesion daily sessions only. The horizontal dashed line is for the average contact time plus 2SDs. For comparison, the contact time is given in the bottom panel for the contralesional hand in Mk-JO (note the different scale in the ordinate). The contact time values saturated at $10 \mathrm{~s}$ indicate that monkey Mk-JO was totally unable to perform the grasping of the pellets on the corresponding daily sessions following the lesion, reflecting the dramatic deficit observed for the contralesional hand

\section{Modified Brinkman board (contact time, 5 pellets) Ipsilesional hand}
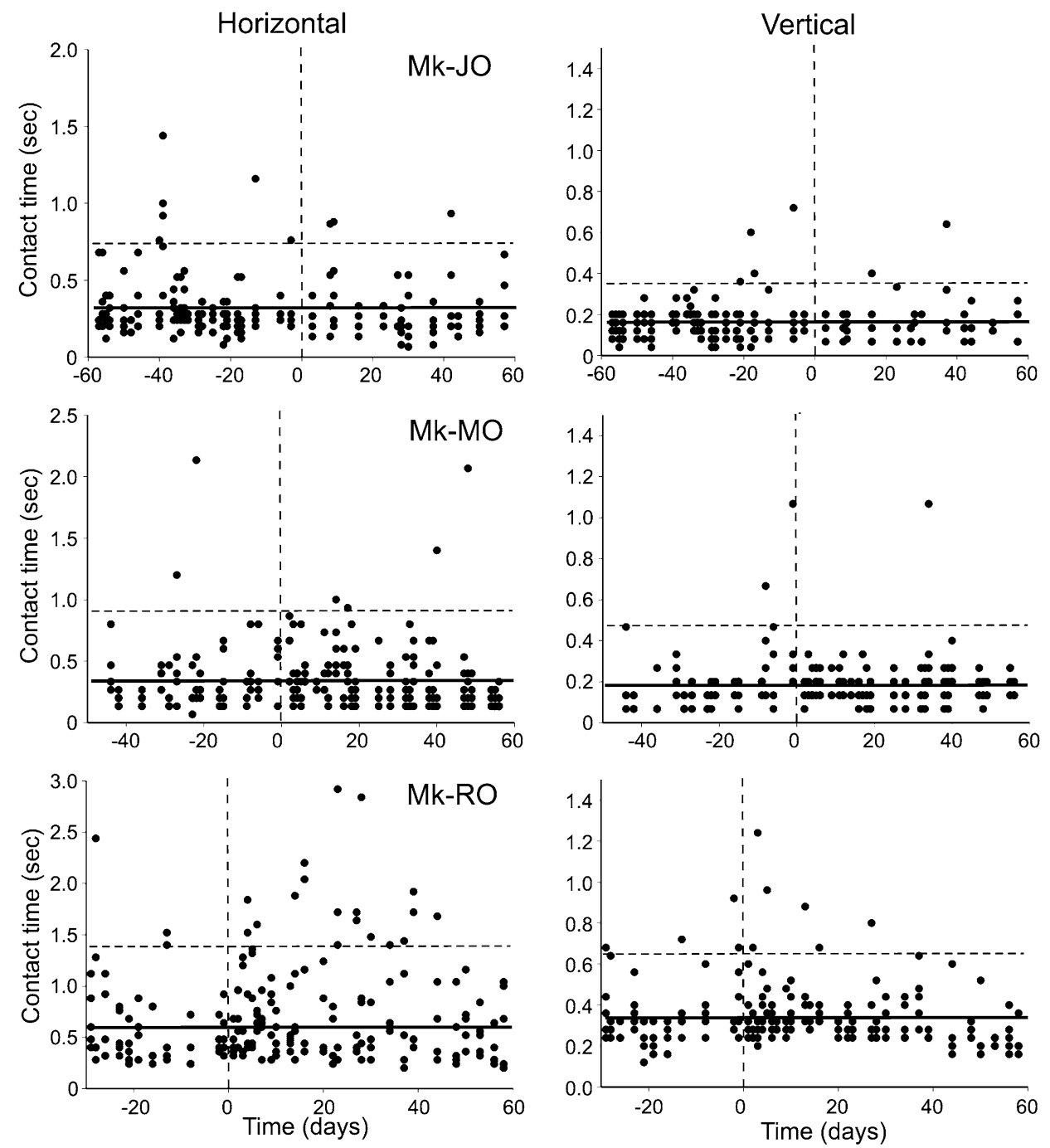

Contralesional hand

Horizontal

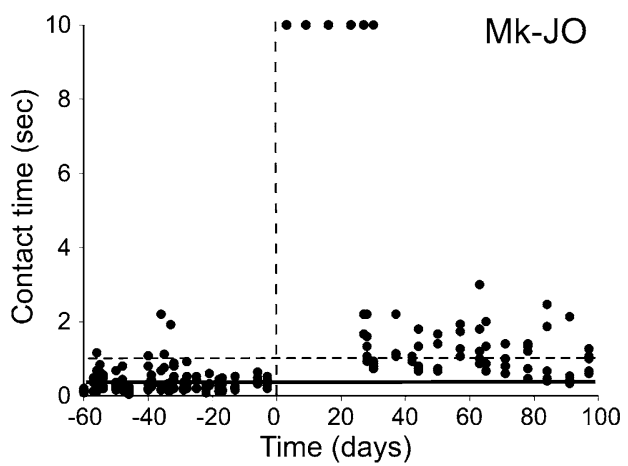

In the other subgroup comprising 7 lesioned monkeys out of 11, as illustrated for Mk-GE (bottom graph in Fig. 2), no significant drop in manual performance was observed for the ipsilesional hand (Table 2), in spite of a massive and long-term deficit in the contralesional hand. Based on the retrieval score data for the Modified 
Fig. 4 Behavioral data (manual dexterity) obtained from three representative monkeys (MkMO, Mk-VA and Mk-RO) for the Brinkman box task, performed with visual feedback. The manual dexterity of the ipsilesional hand is given by the total time needed by the monkey to empty the 20 wells. Along the abscissa, the day of the M1 lesion is at time zero (vertical dashed line). The thick horizontal line is the average total time, computed from the pre-lesion daily sessions only. The horizontal dashed line is for the average total time plus 2SDs. For comparison, the total time is given in the small graphs on the right for the

contralesional hand in each monkey (note the different scale in the ordinate). On the right, the post-lesion period shown on the graphs was set depending on the variable time course of recovery across monkeys. In the top graph (Mk-MO), the arrow points to a daily session in which the monkey took a lot of time to empty the box (probably due to poor motivation on that day), thus representing an outlier data point
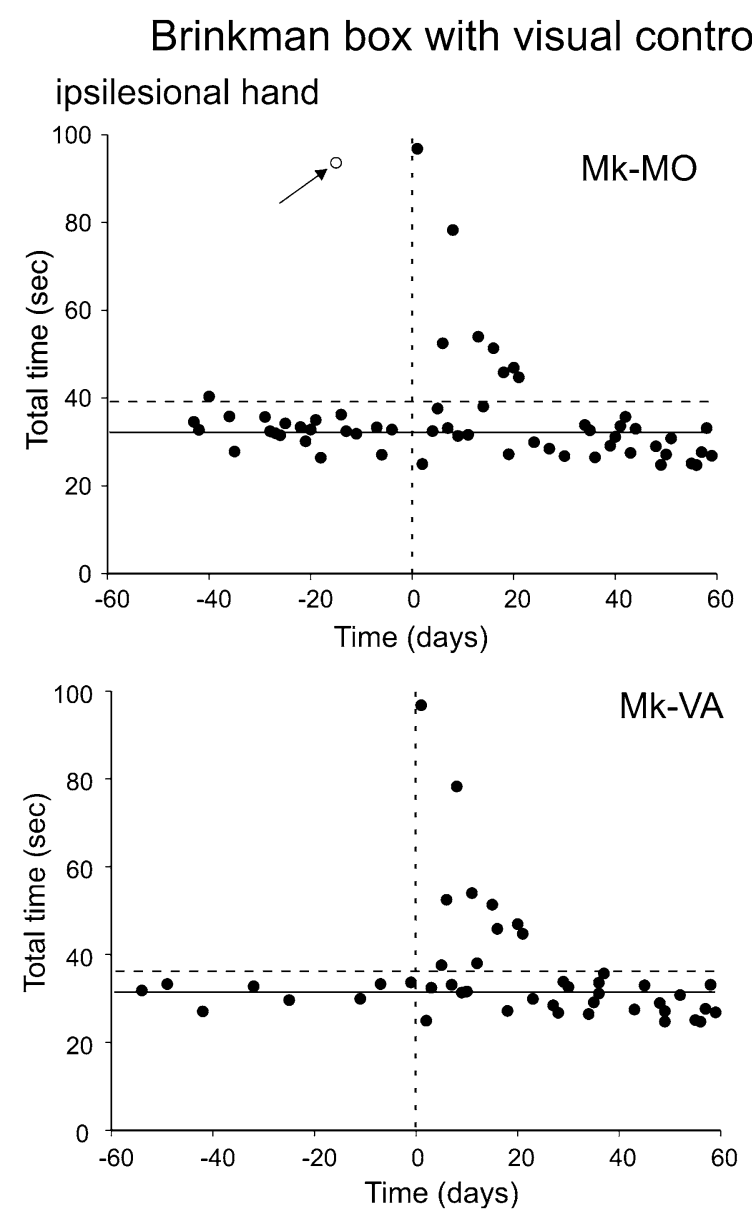
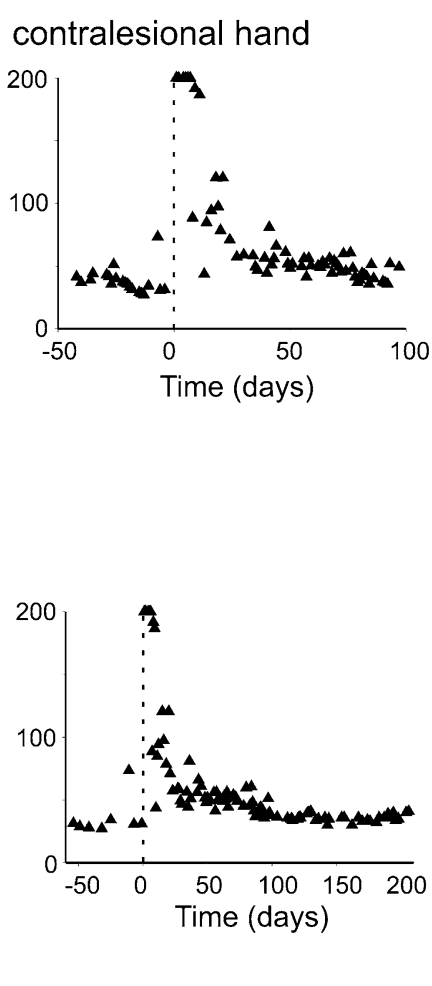

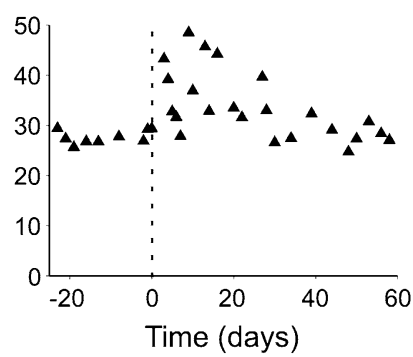

Brinkman Board task, only four monkeys thus exhibited a modest and transient deficit for the ipsilesional hand shortly after the lesion, whereas the majority of monkeys $(n=7)$ did not show any significant impairment.

\section{Modified Brinkman Board test: contact time}

To focus more specifically on the grasping phase of the pellet, reflecting specifically manual dexterity (and thus omitting other components of the task, such as reaching, transporting to the mouth, etc.; see Freund et al. 2009), the parameter contact time measures the time in seconds of contact between the fingers and the pellet within the slot. The shorter the contact time, the more dexterous the monkey during the corresponding trial. The contact time was determined for the first five vertical pellets and the first five horizontal pellets targeted by the monkey on each daily session. Contact time data were thus represented separately 
Table 2 Summary of the effects of M1 lesion on the ipsilesional hand manual performance

\begin{tabular}{|c|c|c|c|c|c|c|c|c|c|c|c|c|}
\hline & $\begin{array}{l}\text { Mk- } \\
\text { CE }\end{array}$ & $\begin{array}{l}\text { Mk- } \\
\text { JU }\end{array}$ & $\begin{array}{l}\text { Mk- } \\
\text { GE }\end{array}$ & $\begin{array}{l}\text { Mk- } \\
\text { RO }\end{array}$ & $\begin{array}{l}\text { Mk- } \\
\text { AV }\end{array}$ & $\begin{array}{l}\text { Mk- } \\
\text { BI }\end{array}$ & $\begin{array}{l}\text { Mk- } \\
\text { VA }\end{array}$ & $\begin{array}{l}\text { Mk- } \\
\text { SL }\end{array}$ & $\begin{array}{l}\text { Mk- } \\
\text { MO }\end{array}$ & $\begin{array}{l}\text { Mk- } \\
\text { JA }\end{array}$ & $\begin{array}{l}\text { Mk- } \\
\text { JO }\end{array}$ & $\begin{array}{l}\mathrm{Mk}^{-} \\
\mathrm{LA}^{\mathrm{a}}\end{array}$ \\
\hline Retrieval score & $\mathrm{N}$ & $\mathrm{N}$ & $\mathrm{N}$ & $\mathrm{N}$ & $\mathrm{N}$ & $\mathrm{Y}$ & $\mathrm{Y}$ & $\mathrm{N}$ & $\mathrm{Y}$ & $\mathrm{Y}$ & $\mathrm{N}$ & $\mathrm{Y}$ \\
\hline Contact time & $\mathrm{N}$ & $\mathrm{N}$ & $\mathrm{Y}$ & $\mathrm{Y}$ & $\mathrm{N}$ & $\mathrm{N}$ & $\mathrm{N}$ & $\mathrm{Y}$ & $\mathrm{N}$ & $\mathrm{N}$ & $\mathrm{N}$ & $\mathrm{Y}$ \\
\hline Total time & - & - & $\mathrm{N}$ & $\mathrm{N}$ & $\mathrm{N}$ & $\mathrm{N}$ & $\mathrm{Y}$ & $\mathrm{Y}$ & $\mathrm{Y}$ & $\mathrm{N}$ & $\mathrm{N}$ & - \\
\hline No. of inj. close to proximal sites ${ }^{b}$ & 5 & 9 & 3 & 6 & - & 9 & 2 & 3 & 10 & 12 & - & - \\
\hline $\begin{array}{l}\text { Average distance to proximal sites } \\
(\mathrm{mm})^{\mathrm{c}}\end{array}$ & 1.5 & 2.6 & 1.3 & 1.4 & - & 1.1 & 1.3 & 1.4 & 1.8 & 0.5 & - & - \\
\hline
\end{tabular}

Effect of unilateral lesion of M1 hand representation on the manual performance with the ipsilesional hand as assessed with three parameters: retrieval score in the Modified Brinkman Board task, the contact time in the Modified Brinkman Board task and the total time in the Brinkman box task. Y ("YES") means that the lesion had an effect, whereas N ("NO") is for an absence of effect, as observed for each monkey. Note that the parameter total time was not measured in the two monkeys, Mk-CE and Mk-JU, as the Brinkman box task was not introduced yet when these monkeys were under study. The Brinkman box task was not tested in the reversible inactivation sessions with muscimol in Mk-LA. In all monkeys, except Mk-LA, the lesion was permanent (infusion of ibotenic acid)

${ }^{a}$ In Mk-LA, a transient lesion was produced by infusion of muscimol in two separate sessions (see Fig. 5)

b The row gives for each monkey the number of sites where ibotenic acid was infused that were close $(\leq 2 \mathrm{~mm})$ to one or several ICMS sites eliciting proximal muscles activation (shoulder or elbow), as illustrated in Fig. 6 for the monkeys Mk-BI and Mk-SL. These data are plotted in Fig. 7a. As the ICMS maps were incomplete in Mk-AV and Mk-JO, this parameter could not be determined

${ }^{c}$ For each site where ibotenic acid was infused and located close $(\leq 2 \mathrm{~mm})$ to a proximal ICMS site (elbow or shoulder), the actual distance between the infusion site and the close proximal ICMS sites were measured and averaged (expressed in mm). These data are plotted in Fig. $7 \mathrm{~b}$. As the ICMS maps were incomplete in Mk-AV and Mk-JO, this parameter could not be determined

for the horizontal and vertical slots (Fig. 3, left and right columns, respectively). During the pre-lesion period, it happened that a few contact times were above the significant level given by the average contact time +2 SDs (Fig. 3). In two representative monkeys (Mk-JO and MkMO), the post-lesion contact times showed a comparable distribution as pre-lesion, indicative of an absence of effect of the lesion on the grasping ability for the ipsilesional hand. Out of 11 monkeys, 8 monkeys exhibited an absence of effect on the contact time parameter (Mk-JA, Mk-JO, Mk-MO, Mk-BI, Mk-JU, Mk-AV, Mk-CE and Mk-VA; see Table 2). In contrast, there was a transient increase of contact time post-lesion for the ipsilesional hand in three monkeys (Mk-SL, Mk-GE and Mk-RO; see Table 2), as illustrated in Fig. 3 for Mk-RO, exhibiting several contact times above the pre-lesion average contact time +2 SDs. In these three monkeys, the effect of the lesion was present for both slot orientations, though it was somewhat more pronounced in the horizontal slots for Mk-RO (Fig. 3) and Mk-SL, whereas for Mk-GE the deficit was more pronounced for the vertical slots. For comparison, the effect of the M1 lesion on the contralesional hand is shown for Mk-JO in the bottom panel of Fig. 3, with a persistent increase in contact time, lasting more than 100 days postlesion, reflecting a massive loss of manual dexterity.

\section{Brinkman box test: total time}

As explained in "Methods", the manual performance was also tested while the monkeys grasped pellets within a restricted space, corresponding to the Brinkman box
(Fig. 1b, right panel). The total time to empty the 20 slots was measured and illustrated for three typical monkeys in Fig. 4. The pre-lesion performance is represented by the average value (horizontal solid line) and a limit for a statistically significant deviation given by the average prelesion total time +2 SDs (horizontal dashed line). The monkeys Mk-MO and Mk-VA both exhibited a significant increase in total time for the ipsilesional hand for just over 20 days post-lesion. This increase in total time is, however, clearly less prominent and more transient than the one observed for the contralesional hand (plots on the right in Fig. 4). A deficit for the ipsilesional hand was also present in Mk-SL (not shown). In contrast, Mk-RO (Fig. 4, bottom) does not show an increase in total time for the ipsilesional hand in the Brinkman box, except the very first post-lesion daily session. The contralesional hand of Mk-RO showed a clear and long lasting increase of total time. As for Mk-RO, no deficit was observed in the Brinkman box task for five other monkeys (Table 2).

\section{Effect of transient (reversible) unilateral motor cortex} lesion (M1) on manual dexterity

The above data were derived from the assessment of manual dexterity in the ipsilesional hand after permanent unilateral lesion of M1 induced by infusion of ibotenic acid. Although it was possible, with our experimental protocol, to still observe the impact on manual performance already few days after lesion, one cannot exclude a kind of rapid re-arrangement of the system of control of ipsilateral manual dexterity, thus masking a possible role 
actually played by the motor cortex on the ipsilateral hand in the normal state. To circumvent this limitation, one may use the approach of pharmacological reversible inactivation, by infusing muscimol unilaterally in the hand representation of M1, as performed in Mk-LA in two separate sessions. On the same daily session, the manual performance was first assessed in the Modified Brinkman Board task immediately before infusion of muscimol (see Table 1). Then, a few minutes after infusion of muscimol, the manual skill task was repeated. As expected, confirming the efficacy of the inactivation, the retrieval score for the hand opposite to the inactivated M1 dropped to zero, indicative of a complete loss of the ability to grasp pellets (not shown; see however Kermadi et al. 1997). In contrast, the hand ipsilateral to the transiently inactivated M1 was still able to grasp pellets, although the retrieval score dropped to some extent as compared to the preinfusion score. Across two distinct reversible inactivation sessions (Fig. 5a for Mk-LA), the retrieval score for the hand ipsilateral to the reversibly inactivated M1 decreased within a range of $30-73 \%$ for the vertical slots and of 25-33\% for the horizontal slots (Fig. 5a; Table 2). Consistent with this drop in retrieval score, the contact time increased after the infusion of muscimol as compared to prior to the infusion (Fig. 5b; Table 2). The increase in contact time was more prominent for the grasping of the pellets from the horizontal slots than for the vertical slots (Fig. 5b), reaching an increase of about $100 \%$ for the horizontal slots (i.e. the time needed for successful grasping doubled).
Are the effects on manual dexterity with the ipsilesional hand (partly) mediated indirectly via proximal muscles?

The transient deficits observed above for the manual dexterity with the ipsilesional hand after unilateral motor cortex lesion may be due to a dysfunction of cortical territories giving rise to the uncrossed corticospinal projection, involved mainly in the control of proximal muscles (e.g. Lemon 2008). Indeed, if some of the injections of ibotenic acid, aimed at the hand representation, spread to more proximal territories (elbow, shoulder), a dysfunction in the reaching phase as well as in the control of forelimb posture may indirectly impact on the manual dexterity. To address this issue, on the ICMS maps, the sites of ibotenic acid infusion close (less than $2 \mathrm{~mm}$ ) to proximal muscles territories were identified (purple x symbols in Fig. 6) and the corresponding real distances (to proximal ICMS sites) in the original $3 \mathrm{D}$ coordinates system were calculated for each of these sites of injection (Fig. 7; Table 2).

The number of sites of infusion of ibotenic acid close to proximal territories was plotted in Fig. 7a for the individual monkeys as a function of the effects observed on the behavioral tasks described above (no effect $=0$; deficit observed for one manual dexterity task $=1$; deficit observed for two manual dexterity tasks $=2$ ). There is no correlation between the number of sites infused close to proximal territories (elbow, shoulder) and the number of tasks for which an ipsilesional deficit of manual dexterity was observed. When plotting the average distance between the infused sites and the closely located proximal territories

\section{A Effect of muscimol inactivation on retrieval score (Modified Brinkman board task)}
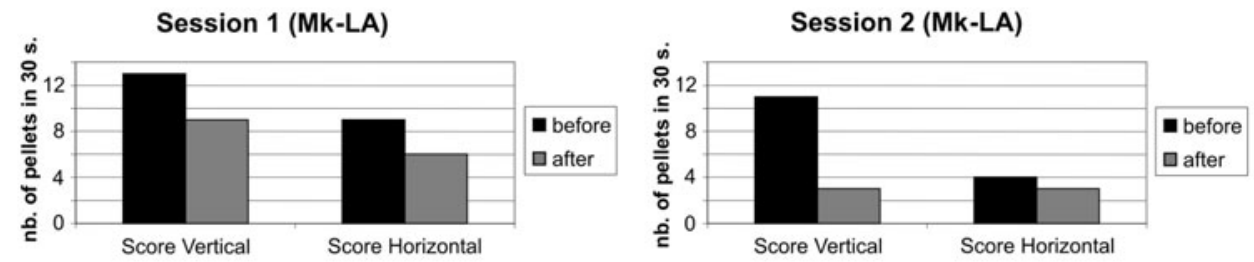

B Effect of muscimol inactivation on contact time (Modified Brinkman board task)

Session 1 (Mk-LA)

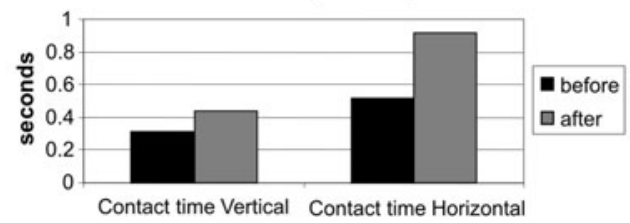

Fig. 5 Immediate effect of reversible inactivation of the M1 hand representation unilaterally in Mk-LA, obtained by infusion of muscimol, on the dexterity of the ipsilateral hand. Two distinct sessions are illustrated (sessions 1 and 2). a The plots show the effect of muscimol infusion on the retrieval score in the Modified Brinkman Board task. b The plots show the effect of muscimol infusion on the

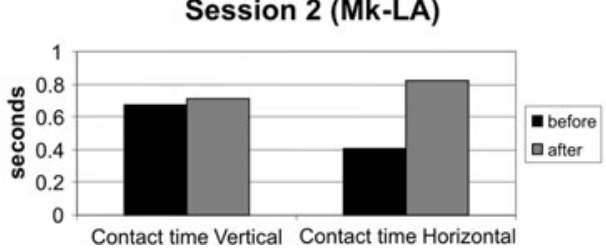

contact time in the Modified Brinkman Board task. a, b The black bars are the pre-infusion data (before inactivation), whereas the gray bars are for the post-infusion data (after inactivation). Retrieval scores and contact times are given separately for the vertical and horizontal slots 


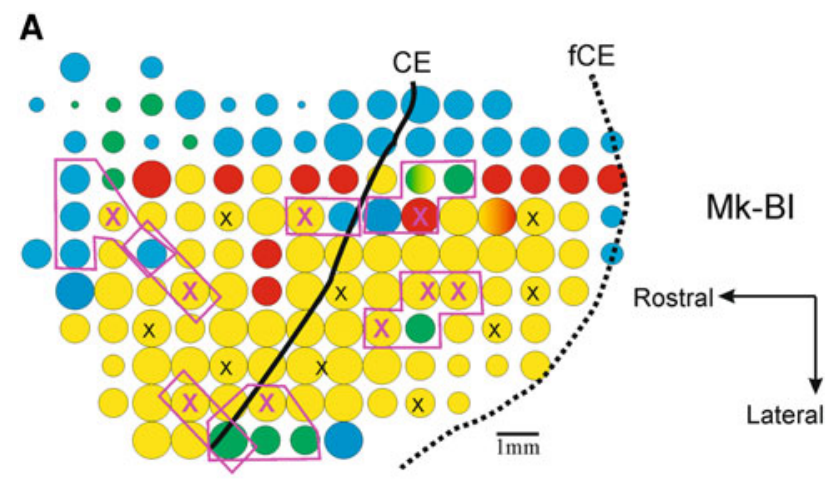

B

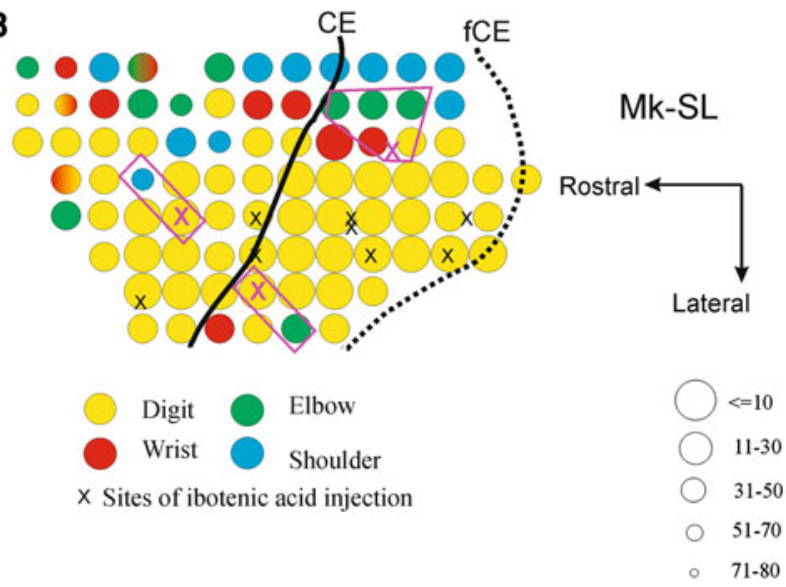

Fig. 6 Representative unfolded ICMS maps (in the left hemisphere) of the forelimb before lesion, derived from two animals, Mk-BI (a) and Mk-SL (b), with positions of ICMS sites selected for infusion of ibotenic acid (x symbols) to produce the lesion of the hand area. The method to unfold the rostral bank of the central sulcus has been described previously (Kaeser et al. 2010). As several electrode tracks running within the same rostrocaudal plane along the rostral bank of the central sulcus are projected on the same line segment, some ICMS sites and/or sites of ibotenic acid infusion may be superimposed. On these surface maps, a few ICMS sites eliciting contralateral finger movements (yellow circles), where ibotenic acid was infused, appear to be located close (less than $2 \mathrm{~mm}$ ) to ICMS sites corresponding to representation of proximal muscles (elbow and shoulder, green and blue circles, respectively). Such sites of infusion of ibotenic acid are depicted by the purple $x$ symbols. The real distance between such sites of infusion of ibotenic acid and the proximal ICMS sites (identified on the maps by purple polygons) was calculated from the original 3D coordinates system. These distance data are presented in Fig. 7 and Table 2. $C E$ central sulcus, $f C E$ fundus of the central sulcus. As coded on the bottom right corner, the size of the circles represents the ICMS threshold at which the just noticeable movement was observed. The body territory (digit, wrist, elbow or shoulder) activated by the ICMS is given by the color code (bottom left). For clarity, at the periphery of the forelimb representation, sites eliciting movements of other territories (e.g. face) or unresponsive were not represented

with respect to the number of manual dexterity tasks for which a deficit was observed (Fig. 7b), there is no systematic relationship either. The data in Fig. 7 thus suggest that the deficits of manual dexterity with the ipsilesional hand do not result from a systematic spread of ibotenic acid to proximal territories in the monkeys exhibiting more deficit than the other animals.

\section{Discussion}

Interpretation of the behavioral data

To the best of our knowledge, the originality of the present study lies in a systematic and quantitative assessment of the manual performance deficit for the ipsilesional hand resulting from unilateral lesion of M1 in non-human primates targeting the hand representation. Indeed, most previous studies on motor cortex lesion in adult monkeys were focused on the contralesional hand (e.g. Passingham et al. 1983; Friel and Nudo 1998; Liu and Rouiller 1999; Frost et al. 2003; Plautz et al. 2003; Pizzimenti et al. 2007; Eisner-Janowicz et al. 2008; Murata et al. 2008; Darling et al. 2009).

Based on 3 parameters characterizing manual performance in 11 macaque monkeys (Table 2), the present study provides evidence that a unilateral permanent lesion of the hand representation in M1 does not induce a systematic and long lasting deficit of motor control for the ipsilesional hand, in contrast to the dramatic deficit observed for the contralesional hand. This conclusion (Figs. 2, 3, 4; Table 2) is in line with the general notion that the corticospinal (CS) projection responsible for fine manual control is largely crossed (about $90 \%$ of CS axons decussate) and terminates on distal motoneurons, whereas the uncrossed CS projection exerts its control mostly on proximal and axial muscles (e.g. Brinkman and Kuypers 1973). For each of the three parameters we assessed, there was, however, a minority of monkeys exhibiting a modest (but statistically significant) deficit of manual performance for the ipsilesional hand, limited to a few days immediately following the lesion. How serious are these deficits? For the retrieval score data, significant deficits were found in 4 monkeys (out of 11), limited however to 1-3 daily sessions immediately after the lesion. The extent of the deficit (i.e. the decrease in retrieval score) ranged from 30 to $50 \%$, with the exception of $80 \%$ in one monkey on one single daily session. Considering the contact time data, the deficits were also moderate (though significant) but, again, in few monkeys ( 3 out of 11). Out of the five contact times recorded for each slot orientation in each daily session, most often only a single measurement exceeded the upper confidence limit derived from the pre-lesion period (Fig. 3). In the three monkeys showing a modest deficit, in very rare daily sessions two recorded contact times within the same daily session exceeded the confidence limit (Fig. 3: Mk-RO). However, such cases were limited to one to two daily sessions. The contact time data are thus 


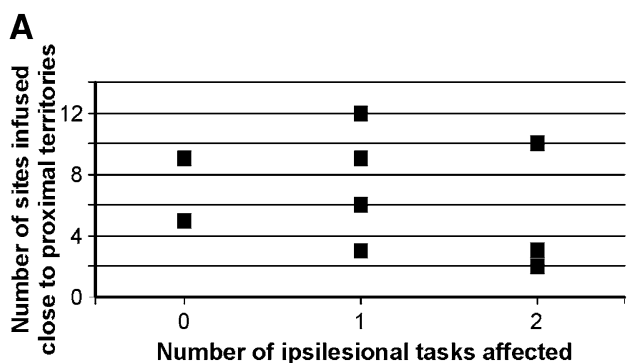

Fig. 7 To assess whether transient deficits for manual dexterity performed with the ipsilesional hand may be due to a spread of ibotenic acid to proximal territories in M1, the number of infusion sites closely located to elbow or shoulder ICMS sites were plotted for individual monkeys as a function of the number of manual dexterity tasks for which a deficit was observed (a none, one or two; see

indicative of a very modest effect of the motor cortex lesion on the ipsilesional hand's manual dexterity per se (specific precision grip ability). As the majority of contact times remained normal in each daily session, it can be concluded that there is no crucial ipsilateral control of the motor cortex on manual dexterity. The lesion of the motor cortex thus appeared to affect slightly more the retrieval score than the contact time. In other words, the effect of the lesion on the ipsilesional hand was more on components of the task distinct from the manual dexterity itself.

Following this deduction, the effect of the lesion on the ipsilesional hand as assessed with the total time to empty the Brinkman box was more prominent, when present, as observed in three monkeys (Mk-MO, Mk-VA and Mk-SL; see Fig. 4). Indeed, in these three monkeys, the effect lasted at least 20 days and was present in about $50 \%$ of daily sessions during this post-lesion time window. This observation is consistent with the notion that the Brinkman box task requires a more precise control of the forelimb posture, as the space to access the slots is more restricted than in the Modified Brinkman Board task. As a consequence, more proximal muscles (in part under the control of the uncrossed CS projection) contribute to performance in the Brinkman box task, which are likely to be more affected by an ipsilateral lesion of the motor cortex than distal muscles specialized for manual dexterity per se. Nevertheless, it remains that the majority of monkeys ( 8 out of 11) did not exhibit a deficit in the Brinkman box task (Table 2), again supporting the notion that the effect of the lesion on the ipsilesional hand is modest, at least for the behavioral tasks considered in the present study. This conclusion is supported by the observation that the deficits seen for the three parameters (Table 2) are not present systematically in the same three to four monkeys. No monkey showed a deficit of the ipsilesional hand for all three parameters, whereas only three monkeys (Mk-SL, Mk-MO and Mk-VA) showed a deficit for two of the three

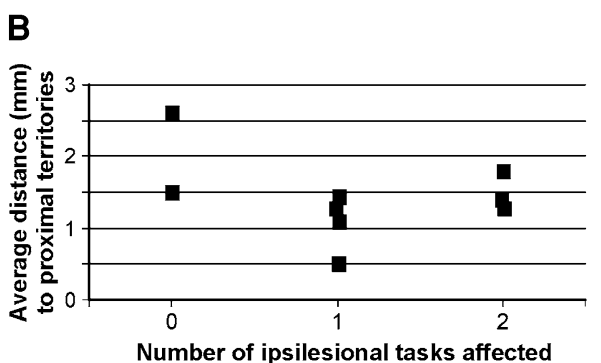

Table 2). Similarly, in $\mathbf{b}$, the average distance from ibotenic acid infusion sites to the closely located proximal ICMS sites was plotted for individual monkeys as a function of the number of manual dexterity tasks for which a deficit was observed. Mk-AV and Mk-JO were not considered as their ICMS map was incomplete (see Table 2)

parameters. Four monkeys exhibited a deficit for only one parameter (Mk-GE, Mk-RO, Mk-BI and Mk-JA). Finally, four monkeys showed no deficits at all, although two of them were not tested for the Brinkman box task (Table 2). Surprisingly, the three monkeys exhibiting deficits of the ipsilesional hand for two of the three parameters were those subjected to anti-Nogo-A antibody treatment. It cannot be ruled out that the presence of the osmotic pumps delivering the antibody during 4 weeks may have contributed, at least in part, and indirectly, to these slight deficits. Considering the monkeys showing deficits of manual performance with the ipsilesional hand for either one or two parameters, there is no obvious correlation with the size and/or the precise position of the lesion (Fig. 1). Moreover, deficits in the ipsilesional hand's manual performance during the days following the lesion of M1 did not correlate with the presence or absence of enhancement of manual performance of the ipsilesional hand on the long-term, found in the monkeys which recovered best their manual performance for the contralesional hand (Kaeser et al. 2010). Finally, there was no systematic relationship between the deficits observed for the ipsilesional hand in some monkeys for one or two motor parameters (Table 2) and the presence/absence of subcortical lesion in the white matter (Table 1). At the other extreme (no deficit), one animal (Mk-AV) was characterized by a very rostral lesion, located mainly in PM, in line with moderate deficits for the contralesional hand and no deficit for the ipsilesional hand.

The deficits observed in the Brinkman box task (increase in the total time that lasted 20 days) for three monkeys after permanent lesion of the motor cortex (Table 2), and while retrieving the pellets from the horizontal slots for Mk-LA that received a reversible lesion, suggest that the impact of the lesion may be indirect via an effect on the posture of the hand. Indeed, the Brinkman box task requires precision control of the hand posture (wrist muscles) within a restricted space in order to perform the 
grasping. In Mk-LA, the predominant effect on the horizontal slots is consistent with the notion that grasping is more difficult from the horizontal slots, requiring an additional postural adjustment of the hand, as compared to the vertical slots (see Freund et al. 2009).

\section{Comparison with previous non-human primate studies}

Few studies on motor cortex lesions have investigated the effects on the ipsilesional hand. In a recent study, marmosets trained to catch a food reward in the "Hill-andValley staircase" test exhibited a deficit lasting about 1 week post-lesion (Bihel et al. 2010), comparable to the transient deficits observed here in a few monkeys. However, the cortical lesions in the marmosets were clearly larger than those in the present study (2-5 times), especially considering the smaller size of the marmoset's brain. As a consequence, the deficit observed in the marmoset for the ipsilesional hand cannot be interpreted as a specific reduction of manual performance, as the lesion spread to more proximal territories in M1, as well as other cortical and subcortical areas. In a previous study, using a similar behavioral test, it was reported that the ipsilesional hand exhibited some deficit, but it was suggested that this deficit was due more to perceptual neglect of the contralesional hemispace than a true motor deficit (Marshall et al. 2003).

A fine motor test (grasping of food pieces) was performed in macaques subjected to a unilateral middle cerebral artery occlusion (Roitberg et al. 2003). As expected, after lesion affecting the motor cortex, the contralesional hand was completely unable to perform the grasping. In contrast, the task was performed successfully with the ipsilesional hand, though more slowly as compared to pre-lesion. The difference, however, was not statistically significant. This result is consistent with a decrease in the retrieval score observed for the ipsilesional hand in the present study in 4 out of 11 monkeys. Once more, the lesion performed by Roitberg et al. (2003) was less constrained to the hand area than that produced in the present study with the infusion of ibotenic acid at sites identified with ICMS.

\section{Possible confounding factors}

The deficit observed for the ipsilateral hand already a few minutes after unilateral infusion of muscimol in M1 in MkLA (Fig. 5), and comparable to the deficits observed in some of the monkeys subjected to permanent lesion (Table 1), allows to rule out that the latter deficits are due to a general degradation of the health condition of the animal following the infusion of ibotenic acid in M1. In fact, except the expected flaccid paralysis restricted to the contralesional hand, the monkeys did not exhibit other pathological signs, in line with a permanent lesion restricted to the hand representation of M1.

Out of 11 monkeys (Table 1), 5 animals were subjected to a treatment, anti-Nogo-A antibody $(n=3)$ or cell therapy $(n=2)$. What may be the influence of these treatments on the manual performance of the ipsilesional hand within the first few weeks post-lesion (up to 60 days)? As mentioned above, in the case of the anti-Nogo-A antibody-treated monkeys, an indirect influence exerted by the osmotic pumps cannot be ruled out. However, a direct negative effect of the anti-Nogo-A antibody treatment is unlikely as one would have expected instead a neuroprotective effect (instead we observed a deficit in the ipsilesional hand in the three treated monkeys). Furthermore, the enhancement of functional recovery for the contralesional hand possibly promoted by the anti-Nogo-A antibody treatment occurs later than 60 days (unpublished data). The delay for enhancement resulting from cell therapy is also longer than 60 days (Kaeser et al. 2011).

Implication of the present study

The variability of the effects of the motor cortex lesion on the ipsilesional hand's manual performance across monkeys (Table 2) may be consistent with the presence of a small territory in M1 from which motor commands are issued toward distal muscles (see Aizawa et al. 1990). Due to its small size and possibly its variable position across monkeys, it is plausible that the lesions performed in the present study involved this "ipsilateral" territory in some monkeys and not in others. The presence of few ICMS sites in M1 activating ipsilateral distal muscles was not found in the present study because, in contrast to the study of Aizawa et al. (1990), only overt movements were investigated here, an approach less sensitive than recording EMG activity. Furthermore, at most ICMS sites, we did not systematically apply high current intensity, to prevent cortical damage, and therefore the ICMS may have been sub-threshold to elicit ipsilateral distal movements. Nevertheless, the present data also suggest an indirect effect via a transient perturbation of the postural hand control, involving primarily more proximal (wrist) muscles.

The general conclusion of the present study that a unilateral lesion of the motor cortex has only modest effects on the performance of the ipsilesional hand thus suggests that the neuronal activities observed in M1 in monkeys performing ipsilateral hand movements (Matsunami and Hamada 1981; Aizawa et al. 1990; Chen et al. 1991; Donchin et al. 1998, 2002; Kermadi et al. 1998, 2000; Kazennikov et al. 1999; Cisek et al. 2003) are most likely related to activation of more proximal muscles (for postural adjustments) and/or activities aimed at preventing simultaneous movements of the opposite hand. From the clinical 
point of view, if a patient exhibits a clear deficit of the ipsilesional hand after cortical lesion, it is likely to be associated to a lesion that is not limited to M1 but rather includes adjacent cortical territories (e.g. premotor cortical areas) more engaged in the control of both hands than M1.

Acknowledgments The authors wish to thank the technical assistance of Laurence Grollimund, Catherine Pythoud, Véronique Moret, Christine Roulin, Françoise Tinguely and Christiane Marti (histology and behavioral evaluations), Josef Corpataux, Laurent Bossy, Bernard Bapst and Bernard Morandi (animal housekeeping), André Gaillard (mechanics), Bernard Aebischer (electronics), Laurent Monney (informatics). Thanks are due to Dr. T. Wannier and Dr. E. Schmidlin for their support and advice in the course of the experiments. Ms Julie Savidan contributed to the assessment of the volume of cortical lesion. We thank Dr. Pamela Banta-Lavenex for editorial comments on the final version of the manuscript. Grant Sponsors are Swiss National Science Foundation, grants No 31-61857.00, 310000-110005, 31003A-132465 (EMR), No 3100A0-103924 (JB), the Novartis Foundation; the National Centre of Competence in Research (NCCR) on "Neural plasticity and repair" and the Christopher Reeves Foundation (Springfield, NJ).

Conflict of interest The authors have no conflict of interest in relation to the present study.

Open Access This article is distributed under the terms of the Creative Commons Attribution Noncommercial License which permits any noncommercial use, distribution, and reproduction in any medium, provided the original author(s) and source are credited.

\section{References}

Aizawa H, Mushiake H, Inase M, Tanji J (1990) An output zone of the monkey primary motor cortex specialized for bilateral hand movement. Exp Brain Res 82:219-221

Alagona G, Delvaux V, Gérard P, De Pasqua V, Pennisi G, Delwaide PJ, Nicoletti F, De Noordhout AM (2001) Ipsilateral motor responses to focal transcranial magnetic stimulation in healthy subjects and acute-stroke patients. Stroke 32:1304-1309

Bawa P, Hamm JD, Dhillon P, Gross PA (2004) Bilateral responses of upper limb muscles to transcranial magnetic stimulation in human subjects. Exp Brain Res 158:385-390

Beaud ML, Schmidlin E, Wannier T, Freund P, Bloch J, Mir A, Schwab ME, Rouiller EM (2008) Anti-Nogo-A antibody treatment does not prevent cell body shrinkage in the motor cortex in adult monkeys subjected to unilateral cervical cord lesion. BMC Neurosci 9:5

Bernard JA, Taylor SF, Seidler RD (2011) Handedness, dexterity, and motor cortical representations. J Neurophysiol 105:88-99

Bihel E, Pro-Sistiaga P, Letourneur A, Toutain J, Saulnier R, Insausti R, Bernaudin M, Roussel S, Touzani O (2010) Permanent or transient chronic ischemic stroke in the non-human primate: behavioral, neuroimaging, histological, and immunohistochemical investigations. J Cereb Blood Flow Metab 30:273-285

Bradnam LV, Stinear CM, Byblow WD (2010) Theta burst stimulation of human primary motor cortex degrades selective muscle activation in the ipsilateral arm. J Neurophysiol 104:2594-2602

Brinkman J, Kuypers HGJM (1973) Cerebral control of contralateral and ipsilateral arm, hand and finger movements in the split-brain rhesus monkey. Brain 96:653-674
Brunet JF, Rouiller E, Wannier T, Villemure JG, Bloch J (2005) Primate adult brain cell autotransplantation, a new tool for brain repair? Exp Neurol 196:195-198

Campbell MJ, Morrison JH (1989) Monoclonal antibody to neurofilament protein (SMI-32) labels a subpopulation of pyramidal neurons in the human and monkey neocortex. J Comp Neurol 282:191-205

Carr IJ, Harrison LM, Stephens JA (1994) Evidence for bilateral innervation of certain homologous motoneurone pools in man. J Physiol 475:217-227

Catalan MJ, Honda M, Weeks RA, Cohen LG, Hallett M (1998) The functional neuroanatomy of simple and complex sequential finger movements: a PET study. Brain 121:253-264

Chen DF, Hyland B, Maier V, Palmeri A, Wiesendanger M (1991) Comparison of neural activity in the supplementary motor cortex and in the primary motor cortex in monkeys performing a choice-reaction task. Somatosens Mot Res 8:27-44

Chen R, Gerloff C, Hallett M, Cohen LG (1997) Involvement of the ipsilateral motor cortex in finger movements of different complexities. Ann Neurol 41:247-254

Chen R, Yung D, Li JY (2003) Organization of ipsilateral excitatory and inhibitory pathways in the human motor cortex. J Neurophysiol 89:1256-1264

Chestnut C, Haaland KY (2008) Functional significance of ipsilesional motor deficits after unilateral stroke. Arch Phys Med Rehabil 89:62-68

Cisek P, Crammond DJ, Kalaska JF (2003) Neural activity in primary motor and dorsal premotor cortex in reaching tasks with the contralateral versus ipsilateral arm. J Neurophysiol 89:922-942

Cole J, Glees P (1952) Ipsilateral impairment following area 4 lesions in monkeys. J Physiol 117:66

Cramer SC, Finklestein SP, Schaechter JD, Bush G, Rosen BR (1999) Activation of distinct motor cortex regions during ipsilateral and contralateral finger movements. J Neurophysiol 81:383-387

Darling WG, Pizzimenti MA, Rotella DL, Peterson CR, Hynes SM, Ge J, Solon K, McNeal DW, Stilwell-Morecraft KS, Morecraft RJ (2009) Volumetric effects of motor cortex injury on recovery of dexterous movements. Exp Neurol 220:90-108

Davare M, Duque J, Vandermeeren Y, Thonnard JL, Olivier E (2007) Role of the ipsilateral primary motor cortex in controlling the timing of hand muscle recruitment. Cereb Cortex 17:353-362

Donchin O, Gribova A, Steinberg O, Bergman H, Vaadia E (1998) Primary motor cortex is involved in bimanual coordination. Nature 395:274-278

Donchin O, Gribova A, Steinberg O, Mitz AR, Bergman H, Vaadia E (2002) Single-unit activity related to bimanual arm movements in the primary and supplementary motor cortices. J Neurophysiol 88:3498-3517

Ehrsson HH, Fagergren A, Jonsson T, Westling G, Johansson RS, Forssberg H (2000) Cortical activity in precision- versus powergrip tasks: an fMRI study. J Neurophysiol 83:528-536

Eisner-Janowicz I, Barbay S, Hoover E, Stowe AM, Frost SB, Plautz EJ, Nudo RJ (2008) Early and late changes in the distal forelimb representation of the supplementary motor area after injury to frontal motor areas in the squirrel monkey. J Neurophysiol 100:1498-1512

Foltys H, Sparing R, Boroojerdi B, Krings T, Meister IG, Mottaghy FM, Töpper R (2001) Motor control in simple bimanual movements: a transcranial magnetic stimulation and reaction time study. Clin Neurophysiol 112:174-265

Freund P, Schmidlin E, Wannier T, Bloch J, Mir A, Schwab ME, Rouiller EM (2006) Nogo-A-specific antibody treatment enhances sprouting and functional recovery after cervical lesion in adult primates. Nat Med 12:790-792

Freund P, Wannier T, Schmidlin E, Bloch J, Mir A, Schwab ME, Rouiller EM (2007) Anti-Nogo-A antibody treatment enhances 
sprouting of corticospinal axons rostral to a unilateral cervical spinal cord lesion in adult macaque monkey. J Comp Neurol 502:644-659

Freund P, Schmidlin E, Wannier T, Bloch J, Mir A, Schwab ME, Rouiller EM (2009) Anti-Nogo-A antibody treatment promotes recovery of manual dexterity after unilateral cervical lesion in adult primates-re-examination and extension of behavioral data. Eur J Neurosci 29:983-996

Friel KM, Nudo RJ (1998) Recovery of motor function after focal cortical injury in primates: compensatory movement patterns used during rehabilitative training. Somatosens Mot Res 15: 173-189

Frost SB, Barbay S, Friel KM, Plautz EJ, Nudo RJ (2003) Reorganization of remote cortical regions after ischemic brain injury: a potential substrate for stroke recovery. J Neurophysiol 89:3205-3214

Ganguly K, Secundo L, Ranade G, Orsborn A, Chang EF, Dimitrov DF, Wallis JD, Barbaro NM, Knight RT, Carmena JM (2009) Cortical representation of ipsilateral arm movements in monkey and man. J Neurosci 29:12948-12956

Glees P, Cole J (1950) Recovery of skilled motor functions after small repeated lesions of motor cortex in macaque. $\mathbf{J}$ Neurophysiol 13:137-148

Gonzenbach RR, Schwab ME (2008) Disinhibition of neurite growth to repair the injured adult CNS: focusing on Nogo. Cell Mol Life Sci 65:161-176

Hermsdörfer J, Goldenberg G (2002) Ipsilesional deficits during fast diadochokinetic hand movements following unilateral brain damage. Neuropsychologia 40:2100-2115

Hermsdörfer J, Blankenfeld H, Goldenberg G (2003) The dependence of ipsilesional aiming deficits on task demands, lesioned hemisphere, and apraxia. Neuropsychologia 41:1628-1643

Hummel F, Kirsammer R, Gerloff C (2003) Ipsilateral cortical activation during finger sequences of increasing complexity: representation of movement difficulty or memory load? Clin Neurophysiol 114:605-613

Jenny AB (1979) Commissural projections of the cortical hand motor area in monkeys. J Comp Neurol 188:137-146

Kaeser M, Wyss AF, Bashir S, Hamadjida A, Liu Y, Bloch J, Brunet JF, Belhaj-Saif A, Rouiller EM (2010) Effects of unilateral motor cortex lesion on ipsilesional hand's reach and grasp performance in monkeys: relationship with recovery in the contralesional hand. J Neurophysiol 103:1630-1645

Kaeser M, Brunet JF, Wyss A, Belhaj-Saif A, Liu Y, Hamadjida A, Rouiller EM, Bloch J (2011) Autologous adult cortical cell transplantation enhances functional recovery following unilateral lesion of motor cortex in primates: a pilot study. Neurosurgery (in press)

Kawashima R, Matsumura M, Sadato N, Naito E, Waki A, Nakamura S, Matsunami K, Fukuda H, Yonekura Y (1998) Regional cerebral blood flow changes in human brain related to ipsilateral and contralateral complex hand movements-a PET-study. Eur J Neurosci 10:2254-2260

Kazennikov O, Hyland B, Corboz M, Babalian A, Rouiller EM, Wiesendanger M (1999) Neural activity of supplementary and primary motor areas in monkeys and its relation to bimanual and unimanual movement sequences. Neuroscience 89:661-674

Kermadi I, Liu Y, Tempini A, Rouiller EM (1997) Effects of reversible inactivation of the supplementary motor area (SMA) on unimanual grasp and bimanual pull and grasp performance in monkeys. Somatosens Mot Res 14:268-280

Kermadi I, Liu Y, Tempini A, Calciati E, Rouiller EM (1998) Neuronal activity in the primate supplementary motor area and the primary motor cortex in relation to spatio-temporal bimanual coordination. Somatosens Mot Res 15:287-308
Kermadi I, Liu Y, Rouiller EM (2000) Do bimanual motor actions involve the dorsal premotor (PMd), cingulate (CMA) and posterior parietal (PPC) cortices? Comparison with primary and supplementary motor cortical areas. Somatosens Mot Res 17:255-271

Kim S-G, Ashe J, Hendrich K, Ellermann JM, Merkle H, Ugurbil K, Georgopoulos AP (1993) Functional magnetic resonance imaging of motor cortex: hemispheric asymmetry and handedness. Science 261:615-617

Lacroix S, Havton LA, McKay H, Yang H, Brant A, Roberts J, Tuszynski MH (2004) Bilateral corticospinal projections arise from each motor cortex in the macaque monkey: a quantitative study. J Comp Neurol 473:147-161

Lemon RN (2008) Descending pathways in motor control. Annu Rev Neurosci 31:195-218

Liu Y, Rouiller EM (1999) Mechanisms of recovery of dexterity following unilateral lesion of the sensorimotor cortex in adult monkeys. Exp Brain Res 128:149-159

Marshall JWB, Ridley RM, Baker HF, Hall LD, Carpenter TA, Wood NI (2003) Serial MRI, functional recovery, and long-term infarct maturation in a non-human primate model of stroke. Brain Res Bull 61:577-585

Matsunami K, Hamada I (1981) Characteristics of the ipsilateral movement-related neuron in the motor cortex of the monkey. Brain Res 204:29-42

Murata Y, Higo N, Oishi T, Yamashita A, Matsuda K, Hayashi M, Yamane S (2008) Effects of motor training on the recovery of manual dexterity after primary motor cortex lesion in macaque monkeys. J Neurophysiol 99:773-786

Netz J, Lammers T, Hömberg V (1997) Reorganization of motor output in the non-affected hemisphere after stroke. Brain 120: $1579-1586$

Noskin O, Krakauer JW, Lazar RM, Festa JR, Handy C, O’Brien KA, Marshall RS (2008) Ipsilateral motor dysfunction from unilateral stroke: implications for the functional neuroanatomy of hemiparesis. J Neurol Neurosurg Psychiatry 79:401-406

Nowak DA, Grefkes C, Dafotakis M, Kust J, Karbe H, Fink GR (2007) Dexterity is impaired at both hands following unilateral subcortical middle cerebral artery stroke. Eur J Neurosci 25: 3173-3184

Park MC, Belhaj-Saif A, Gordon M, Cheney PD (2001) Consistent features in the forelimb representation of primary motor cortex in rhesus macaques. J Neurosci 21:2784-2792

Park MC, Belhaj-Saif A, Cheney PD (2004) Properties of primary motor cortex output to forelimb muscles in rhesus macaques. J Neurophysiol 92:2968-2984

Passingham RE, Perry VH, Wilkinson F (1983) The long-term effects of removal of sensorimotor cortex in infant and adult rhesus monkeys. Brain 106:675-705

Pizzimenti MA, Darling WG, Rotella DL, McNeal DW, Herrick JL, Ge J, Stilwell-Morecraft KS, Morecraft RJ (2007) Measurement of reaching kinematics and prehensile dexterity in nonhuman primates. J Neurophysiol 98:1015-1029

Plautz EJ, Barbay S, Frost SB, Friel KM, Dancause N, Zoubina EV, Stowe AM, Quaney BM, Nudo RJ (2003) Post-infarct cortical plasticity and behavioral recovery using concurrent cortical stimulation and rehabilitative training: a feasibility study in primates. Neurol Res 25:801-810

Porro CA, Cettolo V, Francescato MP, Baraldi P (2000) Ipsilateral involvement of primary motor cortex during motor imagery. Eur J Neurosci 12:3059-3063

Rau C, Plewnia C, Hummel F, Gerloff C (2003) Event-related de synchronization and excitability of the ipsilateral motor cortex during simple self-paced finger movements. Clin Neurophysiol 114:1819-1826 
Roitberg B, Khan N, Tuccar E, Korrlpoliti K, Chu YP, Alperin N, Kordower JH, Emborg ME (2003) Chronic ischemic stroke model in cynomolgus monkeys: behavioral, neuroimaging and anatomical study. Neurol Res 25:68-78

Rosenzweig ES, Brock JH, Culbertson MD, Lu P, Moseanko R, Edgerton VR, Havton LA, Tuszynski MH (2009) Extensive spinal decussation and bilateral termination of cervical corticospinal projections in rhesus monkeys. J Comp Neurol 513: $151-163$

Rouiller EM, Babalian A, Kazennikov O, Moret V, Yu X-H, Wiesendanger M (1994) Transcallosal connections of the distal forelimb representations of the primary and supplementary motor cortical areas in macaque monkeys. Exp Brain Res 102:227-243

Rouiller EM, Moret V, Tanné J, Boussaoud D (1996) Evidence for direct connections between the hand region of the supplementary motor area and cervical motoneurons in the macaque monkey. Eur J Neurosci 8:1055-1059

Rouiller EM, Yu XH, Moret V, Tempini A, Wiesendanger M, Liang F (1998) Dexterity in adult monkeys following early lesion of the motor cortical hand area: the role of cortex adjacent to the lesion. Eur J Neurosci 10:729-740

Sadato N, Campbell G, Ibáñez V, Deiber MP, Hallett M (1996) Complexity affects regional cerebral blood flow change during sequential finger movements. J Neurosci 16:2693-2700

Schmidlin E, Wannier T, Bloch J, Rouiller EM (2004) Progressive plastic changes in the hand representation of the primary motor cortex parallel incomplete recovery from a unilateral section of the corticospinal tract at cervical level in monkeys. Brain Res 1017:172-183

Schmidlin E, Wannier T, Bloch J, Belhaj-Saïf A, Wyss A, Rouiller EM (2005) Reduction of the hand representation in the ipsilateral primary motor cortex following unilateral section of the corticospinal tract at cervical level in monkeys. BMC Neurosci $6: 56$
Sunderland A (2000) Recovery of ipsilateral dexterity after stroke. Stroke 31:430-433

Sunderland A, Bowers MP, Sluman SM, Wilcock DJ, Ardron ME (1999) Impaired dexterity of the ipsilateral hand after stroke and the relationship to cognitive deficit. Stroke 30:949-955

Tsang YM, Chiong F, Kuznetsov D, Kasarskis E, Geula C (2006) Motor neurons are rich in non-phosphorylated neurofilaments: cross-species comparison and alteration in ALS. Brain Res $861: 45-58$

Verstynen T, Diedrichsen J, Albert N, Aparicio P, Ivry RB (2005) Ipsilateral motor cortex activity during unimanual hand movements relates to task complexity. J Neurophysiol 93:1209-1222

Wannier T, Schmidlin E, Bloch J, Rouiller EM (2005) A unilateral section of the corticospinal tract at cervical level in primate does not lead to measurable cell loss in motor cortex. J Neurotrauma 22:703-717

Wassermann EM, Fuhr P, Cohen LG, Hallett M (1991) Effects of transcranial magnetic stimulation on ipsilateral muscles. Neurology 41:1795-1799

Wetter S, Poole JL, Haaland KY (2005) Functional implications of ipsilesional motor deficits after unilateral stroke. Arch Phys Med Rehabil 86:776-781

Yarosh CA, Hoffman DS, Strick PL (2004) Deficits in movements of the wrist ipsilateral to a stroke in hemiparetic subjects. J Neurophysiol 92:3276-3285

Yoshino-Saito K, Nishimura Y, Oishi T, Isa T (2010) Quantitative inter-segmental and inter-laminar comparison of corticospinal projections from the forelimb area of the primary motor cortex of macaque monkeys. Neuroscience 171:1164-1179

Ziemann U, Ishii K, Borgheresi A, Yaseen Z, Battaglia F, Hallett M, Cincotta M, Wassermann EM (1999) Dissociation of the pathways mediating ipsilateral and contralateral motor-evoked potentials in human hand and arm muscles. J Physiol (Lond) 518:895-906 